\title{
Problems of achieving energy efficiency in residential low-rise housing construction within the framework of the resource-saving technologies use
}

\author{
Aleksandr Sekisov* \\ Kuban State Agrarian University named after I.T. Trubilin, 350044, Krasnodar, Russia
}

\begin{abstract}
This article discusses the problems of achieving energy efficiency in residential low-rise housing construction within the framework of the resource-saving technologies use at the federal and regional levels. The need to solve these problems is due to the fact that the industry and transport development, as well as the accompanying increase in energy consumption, including the consumption of end consumers, have led to an acute mankind dependence on energy resources. The increase in energy demand with the simultaneous complication and rise in the cost of energy production, as well as the aggravation of global environmental problems have made energy conservation and energy efficiency the most important development areas in many countries of the world.
\end{abstract}

\section{Introduction}

Energy saving in the modern world is a complex implementation of organizational, legal, technical, technological, economic and other measures aimed at reducing the volume of energy resources used while maintaining the corresponding beneficial effect from their use $[11,12]$. Energy efficiency is a characteristic that reflects the ratio of the beneficial effect from the use of energy resources to the expenditure of energy resources produced in order to obtain this effect. In turn, the action to improve energy efficiency is, in fact, any action (set of actions) taken by a manufacturer or consumer of energy resources, which reduces

\footnotetext{
* Corresponding author: alnikkss@gmail.com
} 
the specific energy intensity of the final product and does not have a negative impact on its other characteristics, or allows improving the characteristics of the final product with constant energy intensity $[2,3,5,9,12]$.

\section{Main part}

\subsection{Priority of energy saving and ways to increase energy efficiency in construction}

As it is shown by our studies in modern residential housing construction, the main consumption of energy is electricity. At the same time, about half of the energy consumed by buildings is accounted for by domestic hot water (DHW). Of the remaining half, about half is due to heat loss due to air exchange, and the other half is also divided in half - into heat loss through window and door openings and heat loss through other enclosing structures (mainly through walls). Thus, the structure of heat energy costs can be represented as follows: DHW $-50 \%$, air exchange $-25 \%$, heat loss through windows and doors $-12.5 \%$, heat loss through the rest of the building heat-shielding envelope $-12,5 \%$.

From the point of view of the control methods application, energy consumption in a building is due to the following components: heat loss through the heat-protective envelope of the building (this heat consumption is regulated by building codes, determined by climatic conditions, as well as the measures taken at the stage of design of thermal protection and construction of buildings); heat losses through ventilation (although these heat losses depend on design decisions and construction measures, they are mainly determined by the building operation, as well as climatic conditions); creating the necessary comfort: DHW, lighting, electrical appliances, elevators and other technological equipment (this energy consumption practically does not depend on design and construction, weakly depends on the climate and is mainly determined by the building operating conditions) [1, 3].

Energy saving measures should be determined depending on the type of energy consumption. The easiest way to regulate thermal protection is at the design and construction stage. It is more difficult when organizing air exchange, since the efficiency of energysaving solutions in the field of ventilation systems depends largely on utilities, the behavior of residents and other factors [1]. In turn, energy saving while ensuring comfortable conditions (DHW, electricity consumption, etc.) can be regulated only by building an optimal system of influence on the end consumers' behavior.

\subsection{Energy consumption and environmental concerns}

Energy industry is a source of adverse environmental impact and one of the main causes of adverse climate change currently taking place. Energy consumes from the environment a huge amount of oxygen, water and fossil resources, producing, in addition to useful energy, 
waste and pollutants, thereby having a significant impact on all the shells of the Earth: the atmosphere, hydrosphere, lithosphere and biosphere. Long-term neglect of this energy consumption aspect and neglect of scale has already led to serious environmental consequences, including an increase in carbon dioxide concentration, climate change. The lack of proper control over the further growth of energy consumption can lead to an ecological crisis, global climate change on Earth and, as a consequence, to a series of natural and social disasters $[5,10,12]$.

\subsection{The role of housing construction in the energy consumption system}

The question of the need to save energy resources in Russia is quite acute. In the report of the American Council for an Energy - Efficient Economy, the low energy efficiency of the Russian economy is noted: in the ranking, Russia took only 17 th place among the 23 studied countries - the largest energy consumers. The document especially noted the high energy intensity of the construction sector and made the recommendations. Also, according to Rosstat, SBS analysts and CE-Energy efficiency center the housing sector of Russia occupies a leading position in the structure of energy consumption [4, 6, 9]. According to the report of the Ministry of Energy, the housing sector also accounts for a significant share of the maximum potential for saving final energy [7]. Such a high potential for energy saving in the housing sector is associated not only with the use of materials of enclosing structures that are ineffective in terms of resistance to heat transfer, but also with poor construction quality, a high degree of physical deterioration of buildings and the lack of energy-saving measures $[5,11,12]$.

The problem of the need to build houses that produce more energy than it is necessary to cover their own needs (a house with a positive energy balance) is currently more and more acute in low-rise building projects. This makes the area particularly attractive for research and investment. It should be noted that the methods of energy saving in low-rise housing construction are currently insufficiently developed and limited. Most of them are associated with accounting and regulation of energy consumption and with an increase in the resistance to heat transfer of enclosing structures. At the same time, an increase in resistance to heat transfer in excess of the regulatory documents' requirements is ineffective, and accounting and regulation of consumption give significant results only in the case of a reconstruction project $[5,11]$.

\subsection{Key challenges in ensuring high energy efficiency}

The limited research in the field of energy saving in low-rise housing construction is associated not only with the restrictions imposed by the regulatory documents' requirements, but also with the peculiarity of market relations, when the direct benefit from the energysaving house operation is usually received by apartment owners, and not by design and construction company or customer. At the same time, the high cost of living space and the 
still low level of education on the issue of energy saving does not contribute to the desire of future apartment owners to overpay for the energy efficiency class of the building or for the energy saving measures taken. In such a situation, the promotion of energy conservation at the state level becomes an important and effective tool $[2,7]$.

\subsection{The main directions of federal and municipal regulation in the field of energy conservation}

When market conditions are not conducive to the development of any direction, government incentives become the most effective tool. Among the potential incentives widely used around the world, it is worth highlighting the payment of bonuses for saved energy, the introduction of incentives, the revision of tariffs, the introduction of regulatory requirements, the conduct of information activities, the promotion of efficient environmental management and education in the field of energy conservation. Complex and intelligent use of incentives can change the current environment in the shortest possible time.

At present, in Russia, state regulation in the field of energy conservation is carried out by a whole range of documents presented by Federal laws, decrees of the President of the Russian Federation, as well as decrees and other documents of the Government of the Russian Federation or its ministries and other state departments of the federal level.

The basis of the energy conservation policy is the Federal Law of the Russian Federation "On Energy Saving and Increasing Energy Efficiency" No. 261-FL of November 23, 2009 and the state program of the Russian Federation "Energy saving and increasing energy efficiency". An important role directly in the construction industry is played by BC 50.13330.2012 "Thermal protection of buildings", where requirements for the level of energy consumption of buildings are established, rules for assigning an energy efficiency class are presented, as well as the recommendations for economic incentives for buildings with a high energy efficiency class are given. Also, in 2016 by the Order of the Ministry of Construction of the Russian Federation No. 399/pr new rules for determining the energy efficiency class of apartment buildings were approved. The new rules make it possible to take into account climatic conditions and bring the domestic classification closer to similar European rules.

\subsection{Key elements of an effective government program to ensure energy efficiency in buildings}

Our studies of the composition and legislative acts' content in the field of ensuring energy saving and increasing the energy efficiency of buildings in the Russian Federation (consistently, as they are approved and published) allow us to draw the following conclusions: there is no consistent state policy on the submitted issue, or this sequence violated; there is no clear relationship in the implementation of the requirements of Presidential Decree No. 889 and federal law No. 261-FL between various ministries of the Russian Federation; the 
requirements of government regulations in terms of ensuring energy efficiency are not met or are being met with a significant lag.

Until now, there are no economic incentive mechanisms in the country for the introduction of energy-saving technologies in construction. For example, in Germany, for this purpose, a list of banks has been defined that issue loans to both individuals and legal entities at interest below market rates for the energy-saving technologies' implementation - for example, for installing a solar collector on the roof of a building or for insulating facades.

Moreover, at the state level, the programs that contradict the principles of energy conservation are being adopted. These include, in particular, the cancellation of daylight saving to summer and winter time. It is also necessary to indicate the federal program "Affordable and Comfortable Housing - to the Citizens of Russia", for the implementation of which it is planned that $50 \%$ of housing should be low-rise. Moreover, in paragraph 5 of Article $11 \mathrm{FL}$ No. 261 it is indicated that energy efficiency requirements do not apply to individual housing construction objects, i.e., on those very low-rise buildings. It should be borne in mind that low-rise buildings consume significantly more specific thermal energy (per $1 \mathrm{~m} 2$ of area or $1 \mathrm{~m} 3$ of building volume) compared to high-rise apartment buildings with the same heat-shielding parameters of external enclosing structures (walls, windows, coverings, etc.) etc.) due to a greater indicator of compactness, reflecting the external enclosing structures' area ratio to the construction volume of the building. This circumstance should be taken into account when designing the thermal protection of individual single-family houses. Requirements for the thermal insulation level of such buildings should be significantly higher than those adopted for multi-apartment high-rise buildings [2, 4, 11].

It should be noted that at the regional level (using the example of the Krasnodar Territory), work is being carried out to ensure the energy efficiency of residential and public buildings as a part of a regional methodological document (RMD) creation. The goals of creating the present RMD are: development of methods for filling in the energy passport of the projected building; development of methods for calculating indicators that quantitatively reflect the characteristics of the projected building energy intensity; development of examples of calculating the energy performance of a building in the form of separate annexes to the document; development of urban planning, architectural planning, engineering and design recommendations to ensure the energy efficiency of the designed buildings, taking into account the climatic and regional design features; unification of all regulatory and legislative requirements in the field of energy saving and energy efficiency improvement within the framework of one methodological document; introduction of innovative energy-saving measures, technologies and materials that ensure a given level of energy consumption [11].

The document includes eight sections: scope; normative references; terms, definitions and abbreviations; initial data for design; general provisions; requirements for the energy passport of the building; the method of filling out the energy passport sections; international systems for ensuring the energy performance of buildings, as well as twenty-five applications. 
The first three sections are generally accepted in the development of any regulatory document.

RMD section four establishes the initial data for the design, where all climatic characteristics of the selected region are summarized: the calculated values of the outside air temperature in the cold season are determined; for the thermal engineering calculation of the enclosing structures, the calculated parameters of the internal air of the corresponding types of buildings and premises are taken; the duration, days, and heating season degree-days HSDD are determined, ${ }^{\circ} \mathrm{C}$-days, heating season for the climatic conditions of the Krasnodar Krai; the average value of the total solar radiation for the heating period on horizontal and vertical surfaces of various orientations is indicated under actual cloudiness conditions $I$ i, $\mathrm{MJ} / \mathrm{m} 2$.

Section five establishes energy efficiency indicators, the procedure for classifying buildings by energy efficiency, the scheme of the annual balance of fuel and energy resources (FER) for buildings, the required (normative) values of the baseline for the indicator characterizing the energy efficiency of the building and the procedure for the gradual reduction of this indicator. The advantage is the fact that it can be used for any preselected value of the normalized (base) generalized indicator of FER annual consumption. It can be the specific consumption of heat energy for heating, ventilation and domestic hot water, it can also be the specific operational energy consumption of the building (in $\mathrm{kg}$ c.f./m2.year), it can be the specific consumption of all types of energy consumption. It is only important to choose an indicator and determine its baseline.

In accordance with the requirements of article 15 of the government decree of the Russian Federation of January 25, 2011 No. 18 on a phased decrease in indicators characterizing the annual specific value of energy consumption in buildings: from January 1, 2011 (for the period 2011-2015), it is allowed to design buildings of energy efficiency classes "C" and higher (with a decrease of at least $15 \%$ in relation to the basic level of indicators characterizing the annual specific value of the consumption of energy resources in buildings); from January 1, 2016 (for the period 2015-2020), it is allowed to design the buildings with classes "B" and higher energy efficiency (with a decrease of at least 30\% in relation to the base level of indicators characterizing the annual specific amount of energy consumption resources in buildings); from January 1, 2020, the buildings design of energy efficiency class "A" is allowed (with a decrease of at least $40 \%$ in relation to the base level of indicators characterizing the annual specific value of energy consumption in buildings).

Separately, it was noted that the assignment of energy efficiency classes "A" and "B" to buildings is carried out only if the following mandatory energy saving measures are included in the project: the use of individual heating points that reduce energy costs for circulation in domestic hot water systems and are equipped with automated systems, control systems and metering of energy resources, hot and cold water consumption; the use of lighting systems for common building premises using energy-saving lamps with energy efficiency class "A" and / or "B", equipped with motion and illumination sensors, as well as reactive power compensation devices for motors in elevator facilities, pumping and ventilation 
equipment; the use of automatically controlled exhaust ventilation with mechanical induction with heat recovery from the exhaust air and natural inflow through ventilation valves in external enclosing structures; integration of renewable energy sources and secondary energy resources into the energy balance of buildings. Thus, classes "A" and "B" energy efficiency can be obtained only if the renewable energy sources and secondary energy resources are included in the energy balance of the building. Thus, the conditions are stimulated for their implementation at the stages of design, construction and buildings' operation.

Section six RMD sets the requirements for the energy passport of the building, which were established in accordance with the current regulatory documents and legislative acts, it was noted, at what stages it is necessary to fill out the energy passport of the facility, who is responsible for the reliability of the data provided.

In section seven RMD the methodology for calculating the indicators necessary for filling out the energy passport form according to Appendix No. 24 as amended by order of the Ministry of Regional Development No. 577 is consistently presented.

Section eight provides a methodology for meeting the requirements for energy efficiency, adopted in European countries and in the United States, including rating systems. This section is introduced with the aim of gradual harmonization of Russian and world requirements for the energy efficiency of buildings, especially taking into account the entry of our country into WTO. Also, section eight presents the methods of scoring when introducing a complex of energy-saving measures in a building in accordance with the requirements of international standards for rating systems of energy efficiency of buildings (LEED, BREEAM) and the Russian standard. OST NOSTROY 2.35.4-2011 Green Building. Residential and public buildings. Rating system for assessing the sustainability of the habitat.

\section{Conclusion}

Increasing the energy efficiency of low-rise residential buildings is an important factor in reducing the energy intensity of the Russian economy, as well as a necessary condition for reducing the anthropogenic impact on the environment. Important problems in this area are: lack of scientific research and low attractiveness of the direction associated with the peculiarity of market relations. An effective tool for overcoming the above-listed problems is state incentives, which have received significant development in recent years. However, at the moment, government incentives are still not efficient enough. Further development of the regulatory framework is required, as well as a system of incentives and benefits for legal entities and individuals that effectively use energy resources.

\section{References}

1. R. Popov, A. Sekisov, D. Gura, B. Nekhay, Y. Abuizeih, Economic and technological factors of improvement of building air conditioning systems, Turismo: Estudos \&Práticas (UERN), Mossoró/RN, Caderno Suplementar 03, 2020, Brazil. 
2. R.A. Popov, A.N. Sekisov, G.V. Mikheev, D.A. Gura, N.A. Shipilova, Journal of Advanced Research in Dynamical and Control Systems, Institute of Advanced Scientific Research, USA $10 \quad$ (2), 2011-2017 http://www.jardcs.org/backissues/abstract.php?archiveid=5293.

3. J. Schnieders, W. Feist, L. Rongen, Energy and Buildings 105, 71-87 (2019)

4. A. Sekisov, L. Ivanov, A. Begiashvili, IOP Conference Series: Materials Science and Engineering 1083, $012072 \quad$ (2021) Russian Federation https://iopscience.iop.org/article/10.1088/1757-899X/1083/1/012072/pdf, doi: 10.1088/1757-899X/1083/1/012072.

5. A. Sekisov, S. Ovchinnikova, V. Grebneva, M. Chernyshova, IOP Conference Series: Materials Science and Engineering 913, 042035 (2020). Russian Federation https://iopscience.iop.org/article/10.1088/1757-899X/913/4/042035/pdf, doi:10.1088/1757-899X/913/4/042035.

6. The 2018 State Energy Efficiency Scorecard. // American Council for an EnergyEfficient Economy http://aceee.org/research-report/u1606.

7. L.S. Ventsyulis, Yu.I. Skorik, A.N. Chusov, Energy saving as the main problem of the fuel and energy complex of Russia (Publishing house of the Polytechnic University, SPb., 2018)

8. Reports and presentations, Ministry of Energy of the Russian Federation http://minenergo.gov.ru/press/doklady

9. L.Ya. Kocharyan, A.A. Savenko, Review of the historical development of the territorial-spatial structure of the city of Krasnodar, Environmental, engineering, economic, legal and management aspects of the development of construction and transport infrastructure, Collection of articles of the International Scientific and Practical Conference FSBEI HE "Kuban State Technological University", Institute of Construction and Transport Infrastructure (FSBEI HE "KubSTU"; International Center for Innovative Research "OMEGA SCIENCE"), 140-147 (2017)

10. Official statistics. Federal State Statistics Service http://www.gks.ru

11. A.N. Sekisov, Prospects for the introduction of modern environmentally-oriented resource-saving technologies at the regional level, Regional strategies and projects: environmental and economic aspects of development and implementation: Proceedings of the international scientific and practical conference, Moscow: Russian Academy of Natural Sciences, 180-186 (2020)

12. A. N. Sekisov, V. V. Klimenko, G. A. Badikyan, I. V. Baleev, T. A. Cherkesov, D. V. Yurovnikov, Database: Design of low-rise residential buildings, Database state registration certificate No. 2021620896 from 28.04.2021, No. 2021620748, application 19.04.2021, publ. 28.04.2021 Issue No. 5 (Access mode: https://www1.fips.ru/registers-docview/fips_servlet?DB=DB\&DocNumber=2021620896\&TypeFile=html). 